\title{
A worldwide survey of the use of simulation in anesthesia
}

\author{
[Une enquête mondiale sur l'usage de la simulation en anesthésie]
}

Pamela J. Morgan MD CCFP FRCPC, ${ }^{*}$ Doreen Cleave-Hogg BA MA PhD $\dagger$

Purpose: To gather information regarding the global use of simulation technology in education, evaluation and research in anesthesia.

Methods: The WorldWide Web was searched and located sites with simulation centres $(n=158)$ were mailed a 67-item questionnaire requesting information regarding demographics, personnel, education use and research involvement. Comments were solicited. Medical school data only are reported in this article.

Results: Two web sites were used to generate the list of simulation centres. Sixty responses were received (38\%), with 4 I emanating from medical schools. Seventy-seven percent of centres were involved in undergraduate education and $85 \%$ in postgraduate education. Few centres were involved in evaluation and/or competency assessments. Sixty-one percent of centres indicated ongoing research with a further $25 \%$ interested in international collaboration. University or university departmental-based funding largely supported simulation technology used in medical schools. The lack of financial and human resources was the single most common problem identified by respondents.

Conclusions: From the survey responses received, opportunities for the simulator to be used for the assessment of performance appear to be under-utilized. This may be due to the lack of research in this area, lack of standardized, valid and reliable tests and the fact that most centres have only recently acquired this technology. Further research supporting the use of the simulator in education and evaluation is required.

Objectif : Rassembler les informations concernant l'usage global de la technologie de la simulation pour la formation, l'évaluation et la recherche en anesthésie.

Méthode : Une recherche sur le Web a permis de localiser les centres de simulation ( $n=158$ ) à qui nous avons envoyé un questionnaire de 67 éléments sur les données démographiques, le personnel, l'utilisation pédagogique et l'implication dans la recherche. Des commentaires ont été sollicités. Seules les données des écoles médicales sont mentionnées dans le présent article.

Résultats : Deux sites Web ont été utilisés pour produire la liste des centres de simulation. Soixante réponses ont été reçues (38\%), dont 41 des écoles de médecine. Soixante-dix-sept pour cent des centres intervenaient dans la formation prédoctorale et $85 \%$ dans la formation postdoctorale. Peu de centres étaient impliqués dans l'évaluation et/ou l'évaluation des compétences. Soixante et un pour cent des centres ont indiqué une recherche en cours et un autre $25 \%$ étaient intéressés à une collaboration internationale. Le financement par l'université ou le service universitaire soutenait largement la technologie de simulation utilisée dans les écoles médicales. Le manque de ressources financières et humaines a été le seul problème le plus fréquent mentionné par les répondants.

Conclusion : Les possibilités d'emploi du simulateur pour l'évaluation de performance semble sous-utilisées. Un manque de recherche dans ce domaine peut en être la cause, ainsi qu'un manque de tests normalisés, valides et fiables et le fait que la plupart des centres n'ont que récemment fait l'acquisition de cette technologie. II faut poursuivre les recherches qui relèvent de l'usage de simulateur en éducation et en évaluation.

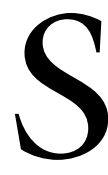

IMULATION technology has experienced an exponential growth over the past few years. Its potential for education and evaluation requires exploration and research. ${ }^{1}$ The simulator offers opportunities for standardized, reproducible critical events in a realistic and safe environment. Both rare and common scenarios can be developed to accommodate teaching and evaluation at

From the Department of Anesthesia, * Sunnybrook \& Women's College Health Sciences Centre, and The Centre for Research in Education, $\uparrow$ University of Toronto, Toronto, Ontario, Canada.

Address correspondence to: Dr. Pamela J. Morgan, Department of Anesthesia, Sunnybrook \& Women's College Health Sciences Centre, Women's College Campus, 76 Grenville Street, Toronto, Ontario M5S 1B2, Canada. Phone: 416-323-6400, ext. 4349; Fax: 416-3236307; E-mail: pam.morgan@utoronto.ca

This study was supported by the Department of Anesthesia, Sunnybrook \& Women's College Health Sciences Centre, Toronto, Ontario, Canada.

Accepted for publication December 20, 2001.

Revision accepted February 1, 2002. 
various educational levels such as undergraduate, postgraduate, continuing medical education and practice assessment. ${ }^{2}$ The ability to videotape sessions allowing feedback and reflection on performance has tremendous possibilities as a learning tool. In spite of the inherent advantages of this environment, there are few indicators as to the extent of high-fidelity patient simulation use around the world.

To address these issues, a survey was designed to gather data regarding simulation technology and its application in education, evaluation and research. In addition, information regarding the financial and resource aspects of acquisition and operation was solicited.

\section{Methods}

A 67-question survey was developed to gather information regarding the use of high-fidelity patient simulators in education and research around the world (available at www.cja-jca.org). Categories of questions included: demographics, personnel, funding for acquisition and maintenance and use in undergraduate, postgraduate and continuing education and practice assessment. Also requested was information on interdepartmental collaboration and research applications. Comments were solicited with specific reference to problems experienced and major benefits attained.

The WorldWide Web was searched using key words: "human patient simulator (HPS), simulation, anesthesia and centre or centre". In addition, individual search strategies, which included the name of the country i.e., "Japan and simulator or simulation", were conducted. The search located 158 simulation centres and the survey was mailed to all centres. After a period of two months, non-respondents who had available e-mail addresses were sent reminder notices and surveys. Data were collected and tabulated in an anonymous fashion. For the purposes of this article, data from simulation centres involved with medical students or residents/faculty in anesthesiology are reported. Comments were categorized. Descriptive statistics were performed for each survey category.

\section{Results}

The WorldWide Web search identified two websites listing current simulator sites and programs: www.anes.rochester.edu/simulate/simusers.htm and www.bristol.ac.uk/Depts/BMSC/centres.htm. The Bristol website listed all simulation centres identified by Medical Education Technologies Incorporated (METI, Sarasota, FL, USA) and MedSim Incorporated (International Headquarters, Kfar Sava, Israel, Corporate Headquarters, Fort Lauderdale, FL, USA) as owning a HPS and included simulation centres that did not have websites. This information generated the list of 158 simulation centres to which surveys were sent. No further simulator sites were located using the alternate search strategy using country name. After the second mailing, 60 surveys were returned for a return rate of $38 \%$. Of the 60 surveys, 41 were from simulation centres involved in education of medical students or anesthesiology residents/faculty, 21 from North America and 20 from other parts of the world. The remaining 19 surveys involved simulator use in nursing, paramedic, respiratory therapist or army training. Ninety-five percent of centres had either a METI HPS $^{\mathrm{TM}}$ (Medical Education Technologies Incorporated, Sarasota, FL, USA) or MedSim HPS ${ }^{\mathrm{TM}}$ (MedSim USA Incorporated, Fort Lauderdale, FL, USA) and one centre had a METI simulator as well as a PediaSim HPS ${ }^{\mathrm{TM}}$ (Medical Education Technologies Incorporated, Sarasota, FL, USA) and an anesthetic computer controlled emergency situation simulator, (ACCESS; A.J. Byrne, Swansea, United Kingdom). Thirty of the 41 centres $(73 \%)$ acquired their simulators within the past five years (1996-2000 inclusive).

The following results report the number of responses to each question; some questions were left unanswered.

Eighty-one percent of centres reported that dedicated personnel were responsible for the operation of the simulator and that the majority of the personnel received funding for this position from either the university or university department. Faculties were involved in all centres with $42 \%$ of institutions indicating that the faculties were reimbursed for their time. Seventy-eight percent of respondents indicated that faculty members were relieved of clinical duties to participate in simulator-related activities.

The funding for simulator acquisition came from 1 ) the university or university department $(76 \%) ; 2$ ) government $(15 \%) ; 3$ ) private sector or other $(13 \%)$; and 4$)$ rented $(3 \%)$. Six centres indicated multiple funding sources. The operation and maintenance costs were supported by 1) university or university department $(83 \%)$; 2$)$ government $(15 \%) ; 3)$ private sector or other $(8 \%)$ with $13 \%$ of centres reporting multiple sources of support.

Seventy-seven percent of centres used the simulator for undergraduate education and $85 \%$ for postgraduate education. Physiology and pharmacology were the most commonly taught topics in the undergraduate program with a wide variety of topics addressed in the postgraduate program (Figure). Few centres reported the use of the simulator for evaluation purposes at any educational level. The majority of continuing medical 


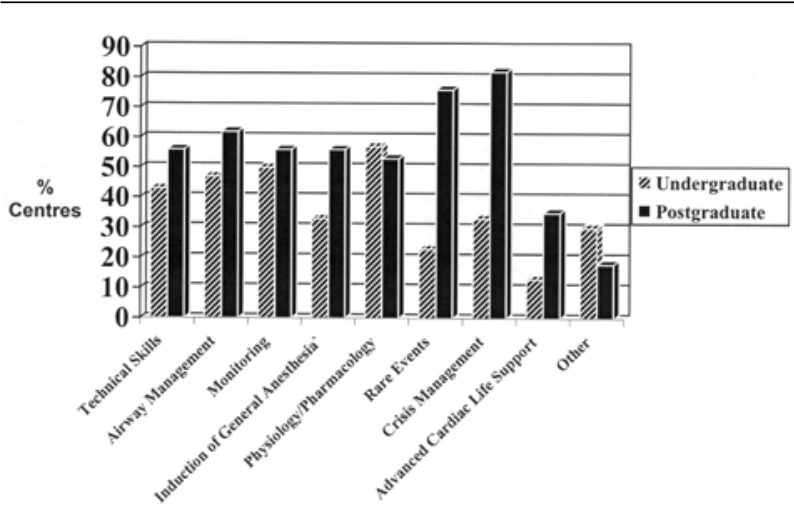

FIGURE Educational uses of the simulator.

education events was funded privately or by participants in the 21 centres reporting the use of the simulator for this purpose. Forty-nine percent of respondents indicated that the simulator should be used for maintenance of certification. However, only $15 \%$ of centres currently used the simulator for practice assessment.

Surgery and nursing were the most commonly identified collaborative disciplines involved in simulator activity: others included aircrew / heli-transport personnel, pharmacy, biomedical engineering and dentistry.

The activities related to research and publications are summarized in Table I. Anecdotal comments regarding problems and benefits of simulator education and evaluation were transcribed and categorized using key words (Table II).

\section{Discussion}

The HPS has not been demonstrated to be a superior tool for learning when compared to existing methods and further study regarding the validity of simulation performance assessments is needed. ${ }^{3-6}$ Despite limited research involving the HPS, acquisition of this expensive technology has increased exponentially. Our search located 158 centres whereas in 1997, Shimada et al. identified only 29 institutions involved in education and training of physicians in anesthesia and other specialties and allied medical professionals. ${ }^{7}$ The number had increased to 70 by $1998 .{ }^{8}$ At the end of November 2001, the Bristol Medical Simulation Centre, www.bristol.ac.uk/Depts/BMSC/centres.htm identified 207 simulation centres worldwide.

Research into the value of the HPS in education, evaluation and research in anesthesia should be encouraged.
TABLE I Research uses of the simulator ( $n=41$, results expressed in \% respondents)

Ongoing simulator research 61

Simulator research in the past 49

Plan to do simulator research in the future? 83

Interest in collaborating in international research $\quad 86$

projects involving the simulator

What are the barriers to simulation research?

$\begin{array}{ll}\text { Lack of funding } & 51 \\ \text { Lack of faculty resources } & 27 \\ \text { Lack of interest } & 0 \\ \text { Lack of subjects } & 3 \\ \text { Lack of institutional support } & 3 \\ \text { Other: } & 12\end{array}$

Have you published papers related to work in your simulator?

Do you perceive any barriers to the publication of simulator-based studies in peer-reviewed journals?

If yes, please identify those perceived barriers:

- journals do not seem to understand educational research

behavioral science focus

- difficulty in standardizing simulation scenarios

- it's difficult for reviewers to critique

TABLE II Most commonly identified categories of problems and benefits of simulation technology from written comments

\begin{tabular}{lclc}
\hline Problems & $\%$ & Benefits & $\%$ \\
\hline $\begin{array}{l}\text { Lack of financial resources } \\
\text { Lack of human resources }\end{array}$ & 18 & $\begin{array}{l}\text { Experiential learning } \\
\text { Management of critical } \\
\text { or rare events }\end{array}$ & 66 \\
Technical problems & 18 & $\begin{array}{l}\text { Undergraduate } \\
\text { educational tool }\end{array}$ & 21 \\
$\begin{array}{l}\text { Lack of time } \\
\text { Lack of validation of }\end{array}$ & 16 & $\begin{array}{l}\text { Patient safety } \\
\text { education or evaluation model }\end{array}$ & $\begin{array}{l}\text { Reproducibility } \\
16\end{array}$ \\
\hline
\end{tabular}

$\%=$ percentage of comments mentioning each respective item.

\section{References}

1 Gaba DM, DeAnda A. A comprehensive anesthesia simulation environment: re-creating the operating room for research and training. Anesthesiology 1988; 69: 387-94.

2 Issenberg SB, McGaghie WC, Hart IR, et al. Simulation technology for health care professional skills training and assessment. JAMA 1999; 282: 861-6.

3 Morgan PJ, Cleave-Hogg D. Evaluation of medical students' performance using the anaesthesia simulator. Med Educ 2000; 34: 42-5.

4 Morgan PJ, Cleave-Hogg DM, Guest CB, Herold J. Validity and reliability of undergraduate performance assessments in an anesthesia simulator. Can J Anesth 2001; 48: 225-33. 
5 Devitt JH, Kurrek MM, Cohen MM, et al. Testing internal consistency and construct validity during evaluation of performance in a patient simulator. Anesth Analg 1998; 86: 1160-4.

6 Morgan PJ, Cleave-Hogg D, McIlroy J, Devitt JH. A comparison of experiential and visual learning for undergraduate medical students. Anesthesiology 2002; 96: 10-6.

7 Shimada $\Upsilon$, Nishiwaki K, Cooper JB. Use of medical simulators subject of international study. J Clin Monit Comput 1998; 14: 499-503.

8 Kapur PA, Steadman RH. Patient simulator competency testing: ready for takeoff? Anesth Analg 1998; 86: 1157-9. 